\title{
Clinical and Microbiological Characterization of the Urinary Infections in Patients with Neurogenic Bladder
}

\section{Elizabeth Hernández González ${ }^{1}$, Esteban Alberti Amador ${ }^{2 *}$ and Javier Rivero Ojeda ${ }^{3}$}

${ }^{1}$ Specialist in Internal Medicine and Infectology, Spinal Cord, Neuromuscular and Multiple Sclerosis Clinic, International Center for Neurological Restoration, Cuba ${ }^{2}$ Specialist in Microbiology, Molecular Biology Department, International Center for Neurological Restoration, Cuba

${ }^{3}$ Specialist in Urology, Center for Medical-Surgical Research, Cuba

*Corresponding Author: Esteban Alberti Amador, Specialist in Microbiology, Molecular Biology Department, International Center for Neurological Restoration, Cuba.
Received: January 27, 2021

Published: March 11, 2021

(C) All rights are reserved by Esteban Alberti

Amador., et al.

\begin{abstract}
Introduction: Complicated urinary tract infection is a very frequent comorbidity in patients with sequelae of neurological diseases, which increases the consumption of antimicrobials and the circulation of resistant germs.

Objective: Carry out clinical-microbiological evaluation of urinary tract infections in patients with neurogenic bladder as well as draw treatment strategies based on the best available clinical evidence.

Method: We conducted a prospective descriptive study for 1 year, in 43 patients treated at CIREN, who underwent a neuro-restorative treatment program with a diagnosis of spinal cord injury (32), demyelinating disease (6), degenerative disease of the central nervous system (3) and static brain injury (2), which present neurogenic bladder among the sequelae and present urinary tract infection during hospitalization.

Results: 112 episodes of urinary infection were diagnosed: acute pyelonephritis in 28 episodes and lower urinary tract infection in 84 episodes, with Escherichia coli (E. coli) in $57.6 \%$ being isolated as the most frequent etiological agent, P. mirabilis $25 \%$ and Klebsiella pneumoniae, (K. pneumoniae). 13.4\%. Risk factors associated with neurogenic bladder: permanent or intermittent catheter 23.2 and $62.7 \%$ respectively. The sensitivity pattern for amikacin and carbapenems was $100 \%$, while the resistance pattern for sulfaprim, penicillins with beta-lactamase inhibitors and ciprofloxacin varied between 20 and $75 \%$ are the most frequent clinical forms of urinary tractus infectious in patients with neurogenic bladder; the common risk factor is intermittent or permanent bladder catheterization, with E coli being the most frequent etiological agent of these episodes.
\end{abstract}

Keywords: Urinary Tract Infection; Neurogenic Bladder; Resistance Antimicrobials

\section{Introduction}

Complicated urinary tract infection (cUTI) is an inflammatory process determined by the invasion and multiplication of any mi- croorganism, from the urethra to the kidney, in a urinary tract with anatomo-functional alterations or the presence of an underlying 
disease that interferes with the mechanisms of host defense can present with a variety of clinical syndromes, the etiology of which can be similar to uncomplicated urinary tract infections, but microorganisms show greater resistance to antibiotics, due to frequent recurrences and prolonged antimicrobial cycles [1]. For these purposes, it is necessary to have diagnostic tools and multidisciplinary therapeutic management, since these patients present associated with their neurogenic bladder (NV) other complications such as vesico-ureteral reflux, high post-voiding residues, high bladder pressures, lithiasis, diverticula, kidney failure which can deteriorate the already injured urinary tract, requiring multiple invasive procedures for its management [2].

According to epidemiological data, 70 - $80 \%$ of UTIc are attributable to the use of urinary catheters, being associated with bloodstream infections, especially in patients at higher risk: prolonged catheters, diabetic patients, immunocompromised patients, the elderly [3]. Those related to health care contributes to the circulation of multi-resistant bacterial strains, the emergence of different uropathogens, such as enterobacteria, producers of extended spectrum beta-lactamases (BLES) and carbapenemases, increasing the consumption of antibiotics, urinary tract complications, costs economic health system and neurological patients, also interfere with adequate rehabilitation, within this group, patients with spinal cord injury (SCI) are the ones with the highest incidence of urinary tract infections, although they are also reported in patients with diseases neurodegenerative diseases such as Parkinson's disease (PD), cerebrovascular disease, dementias, and multiple sclerosis (MS) [4-6].

The pathogenesis of cUTI is equally complex and is influenced by multiple bacterial, immunological, anatomic, urodynamic, and genetic factors related to the location, course, and prognosis of the infection [7]. Advances in this regard have created the basis for new therapeutic options, both for the use of vaccines and for molecules specially directed to attack said virulence factors of enterobacteria [8].

\section{Objective of the Study}

The objectives of this work were to carry out an adequate clinical-microbiological characterization of urinary tract infections in patients with neurogenic bladder, to evaluate associated risk factors and to draw up antimicrobial treatment strategies based on the resistance sensitivity pattern of the most frequent isolated germs.

\section{Materials and Methods}

Universe of work: A prospective uncontrolled study was carried out and the study universe was made up of patients admitted to CIREN who carry out the neurological restoration program between the years 2018-19, taking as inclusion criteria that they present sequelae of a neurological disease, with bladder neurogenic disease and the presence of urinary tract infection diagnosed by urine culture during the hospitalization period. From the total, a sample of 43 patients was selected, who were followed in their evolution between 5 - 12 weeks, with the prior informed consent of the patient and the family. A neuro-urological evaluation protocol already established in the institution is applied to the patients (Table 1), which is carried out as part of the evaluation and treatment program.

\section{Samples}

A sample of urine or secretions from the lower genitourinary tract is collected in the morning, in patients with an indwelling catheter, the catheter is changed 8 hours prior to taking the sample, by means of intermittent sterile catheterization or lurking sample, using sterile containers duly labeled and sent to the laboratory to be processed by a semi-automatic system, Diramic 10 for urine culture, which allows the rapid determination of bacteria in 4 hours, as well as the performance of the antibiogram [12].

The analysis and interpretation of the data is carried out based on the guidelines of the National Committee for Clinical Laboratory Standards of the United States of America [13]. The results are arranged in tables and graphs for your understanding. The discussion is carried out through the interrelation between the results and the theoretical framework, following the order of the objectives set, in such a way that general judgments could be established as conclusions to respond to these objectives.

The collected data were incorporated into a computational database and the Stadist version 6 program or Microsoft Office (Excel) 2000 was used for data processing.

\section{Results}

Symptoms and signs of acute pyelonephritis occurred in 28 episodes (25\%), not accompanied by bacteremia demonstrated in any 
I. Carry out questioning and physical examination, to evaluate the neurological history of the patient with urological dysfunction of the urinary tract, carry out a voiding diary and current status of their bladder and sexual function, as well as a general and system physical examination, emphasizing:

a. Background:

i. High or low urinary infections.

ii. Previous use of antibiotics or urinary antiseptics.

iii. Urological surgeries and associated complications.

iv. Current method of bladder evacuation (voluntary urination or not, if it is with the help of evacuation maneuvers: Valsalva or Credé), if it is by permanent or intermittent catheterization, if it is due to overflow, if there is a sensation or not of a full bladder, episodes of urgency/incontinence, if your bladder capacity or volume is quantified, as well as the presence of post-voiding residue, as well as related dysautonomic disorders).

v. Previous urine cultures

b. Studies to be carried out in the evaluation:

i. Culture and Uroculture.

ii. Renal, bladder and prostate ultrasound. Measure postvoid residue.

iii. Direct vaginal discharge and culture (for women).

iv. Serum prostate antigen (PSA) if you are a man.

v. It is necessary to record the clinical data of the presence of neurogenic intestine, and method of intestinal evacuation.

II. Once all these results have been received and with the updated voiding diary:

1. The neurogenic bladder type will be clinically classified $[9,10]$.

2. The results of the cyturia and urine culture will be evaluated, making clinical correlation and classification of the infection if they are positive, to decide treatment according to recommendation guidelines.

3. The diagnosis of the clinical form of urinary infection will be made according to clinical, microbiological criteria [11].

III. Additional urological studies will be requested if the initial evaluation finds: kidney or bladder lithiasis, dilation or stenosis of the excretory system, malformations or tumors, or in any situation that the attending physician trained in the management of neurogenic bladder considers, for the subsequent specialized assessment.

Table 1: Neuro-urological evaluation protocol.

episode. Fever as the only presenting symptom or associated with headache, chills, general malaise, lumbar pain, abdominal pain, hematuria or atypical symptoms. Lower urinary tract infection occurred in 84 episodes (75\%), in different clinical forms: recurrent symptomatic bacteriuria (29.4\%) and cystitis (16.9\%), especially after removal of a catheter, with increased of frequency, dysuria; atypical symptoms with increased spasticity or muscle spasms, incontinence episodes, difficulty passing the catheter, dysautonomic disorders (dysreflexia) with hypertension, bradycardia, sweating, anxiety and changes in the physical characteristics of the urine; Asymptomatic bacteriuria present in $13.3 \%$ of the episodes, with positive culture in the absence of symptoms, others such as vaginitis, urethritis or epididymitis, with a lower prevalence.

With respect to sex, infection prevailed in males (31 male and 12 female patients with a 1.3/1 ratio), unlike the UTI shown by the general population, which is related to the constitution of the sample, where $74.41 \%$ were patients with spinal cord injuries, a disease predominantly male.

The most frequently occurring risk factors (Table 3), VN with permanent catheter in $23.2 \%$ or intermittent in $62.7 \%$, history of a previous diagnostic procedure or surgery in $18.5 \%$ of patients, 


\begin{tabular}{|l|c|c|c|}
\hline & Men & Woman & \% \\
\hline Acute pyelonephritis & 16 & 12 & 25 \\
\hline Lower UTI & 48 & 36 & 75 \\
\hline Cystitis & 11 & 8 & 16.9 \\
\hline Urethritis & 2 & 2 & 3.5 \\
\hline Vaginitis & - & 9 & 8.03 \\
\hline $\begin{array}{l}\text { Recurrent symptomatic } \\
\text { bacteriuria }\end{array}$ & 21 & 12 & 29.4 \\
\hline Asymptomatic bacteriuria & 10 & 5 & 13.3 \\
\hline Epididymo-orchitis & 4 & 3.5 & \\
\hline Total & 64 & 48 & - \\
\hline
\end{tabular}

Table 2: Clinic presentation of urinary infection.

other abnormalities such as diverticula, lithiasis, stenosis urethral were found in $4.6 \%, 11.6 \%$ and $4.6 \%$ respectively. The susceptibility pattern of $E$. coli and Proteus spp is shown, whose sensitivity to amikacin and carbapenems is found in $100 \%$ of the isolated strains (See graph 2 and 3), in relation to cefepime, the sensitivity remains above $80 \%$, while for sulfaprim the resistance of $E$. coli is greater than $70 \%$, nalidixic acid $80 \%$ and fluoroquinolones type ciprofloxacin between $60-75 \%$, which prevents the empirical or prophylactic use of these antimicrobials in urinary infections. In relation to penicillins with beta-lactamase inhibitors (IBL), the germs showed a resistance between $40 \%$ for amoxicillin/IBL in E. coli and $60 \%$ for piperacillin/IBL for Proteus sp.

\begin{tabular}{|l|c|c|}
\hline \multicolumn{1}{|c|}{ Risk Factors } & No. Patients & Percent \\
\hline Indwelling catheter & 10 & 23.2 \\
\hline Diverticula and Pseudodiverticula & 3 & 4.6 \\
\hline Renal or bladder lithiasis & 5 & 11.6 \\
\hline Previous cystography & 6 & 13.9 \\
\hline Intermittent catheterization & 27 & 62.7 \\
\hline Surgical procedure & 2 & 4.6 \\
\hline Immunosuppression & 3 & 7.5 \\
\hline Only neurogenic bladder & 8 & 18.6 \\
\hline Urethral stenosis & 2 & 4.6 \\
\hline Others (double excretory system) & 2 & 4.6 \\
\hline Pressure ulcer* & 8 & 18 \\
\hline
\end{tabular}

Table 3: Risk factors in patients with urinary tract infections associated with neurogenic bladder.

*: Comorbidity present in patients with spinal cord injury.
Graph 1: Microorganisms isolated in urocultures.
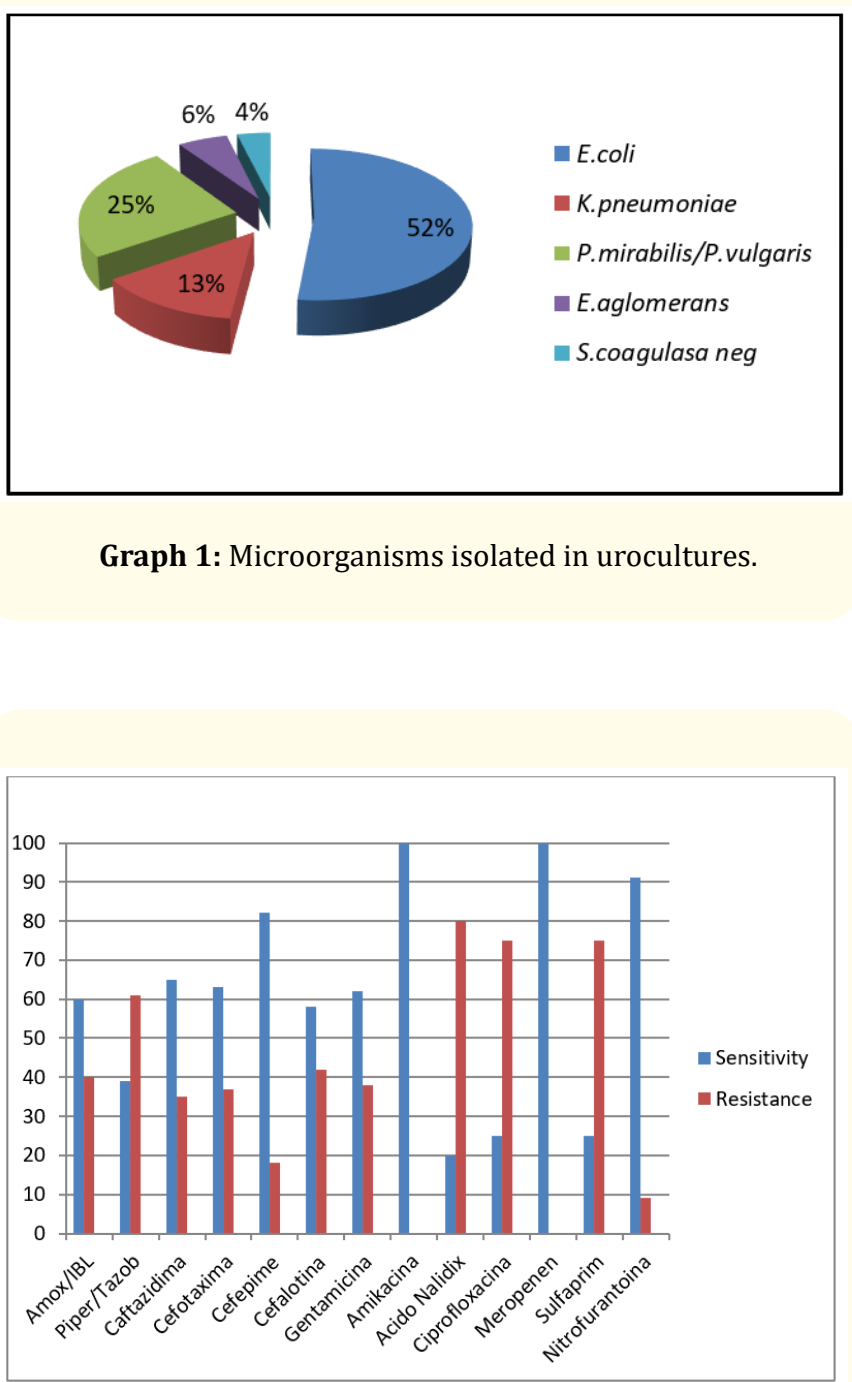

Graph 2: Sensitivity-resistance pattern of E. coli.

\section{Discussion}

Recurrent symptomatic bacteriuria and acute pyelonephritis are the most frequent clinical forms of cUTI in patients with neurogenic bladder, with a predominance of lower urinary tract involvement, which involves pathogenic mechanisms typical of enterobacteria, the presence of virulence factors that intervene in the adherence of microorganisms to the uroepithelium, the presence of biofilms that favor colonization as well as the reduction of the defenses of a functionally and nutritionally affected bladder [14- 


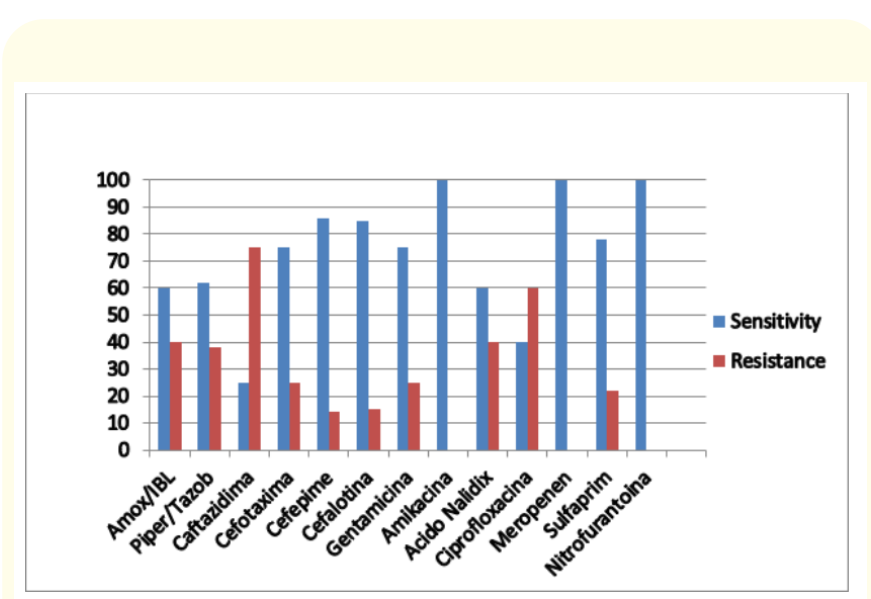

Graph 3: Sensitivity resistance pattern for Proteus spp.

16] but regardless of the contribution that each pathogenic pathway has in the historical model of infection, it has been proposed that in these patients, they only explain approximately $50 \%$ of the episodes of recurrence of symptoms, where the bacterial strains are genetically identical [17]. It has been observed that both relapses and re-infections are related to the existence of an intracellular reservoir of bacteria in the bladder mucosa, which would explain the frequency of therapeutic failure and antimicrobial resistance $[5,18]$.

This pathogenic mechanism would cause a cascade of events that promote infection and recurrence: bacterial replication in the bladder lumen, adherence and invasion of the uroepithelium, internalization with endosome formation, intracellular bacterial replication, bacterial morphological and functional modifications, with resistance to the mechanisms of host defense, escapes from antimicrobial action and defense mechanisms, to restart the process $[8,19]$.

In asymptomatic bacteriuria $(\mathrm{AB})$ from the pathogenic point of view in the patient with $\mathrm{NB}$, it has been proposed in the first place that uropathogens lose the expression of many virulence factors and have little capacity to stimulate an adequate immune response in the mucosa uroepithelial, causing that some of these patients can be asymptomatic carriers for long periods of time, and secondly, the lack of response of the mucosa, being also a protective mechanism to avoid kidney damage; this has been demonstrated in studies conducted in BA children [20]. Therefore, therapeutic or prophylactic antimicrobial treatment is not recommended in asymptomatic bacteriuria, except in special populations (patients who will undergo invasive procedures of the urinary tract where bleeding, immunosuppression, vesico-ureteral reflux are expect- ed).

Therefore, therapeutic or prophylactic antimicrobial treatment is not recommended in asymptomatic bacteriuria, except in special populations (patients who will undergo invasive procedures of the urinary tract where bleeding, immunosuppression, high-grade vesico-ureteral reflux, pregnancy) are expected, since it does not reduce the incidence of the symptomatic episode and the subsequent recurrence by more resistant germs is avoided [21].

Microbiological isolates from patients with neurogenic bladder-associated UTI tend to be similar to uncomplicated infections, however these microorganisms have greater resistance to antibiotics and higher rates of treatment failure when the underlying abnormality cannot be corrected; In the reported series, E. coli is maintained as the predominant germ, however in a much lower proportion in relation to other reports, with an increased trend of isolations of other enterobacteria such as Proteus sp, K. pneumoniae and E. aglomerans, (Graph 1 ), behavior that could be explained by recurrent episodes of asymptomatic bacteriuria and infection with repeated therapeutic courses of antibiotics that occur in patients with cUTI, and that favor changes in the intestinal flora as well as the appearance of emerging uropathogens [22].

We must bear in mind that in UTI of patients with permanent and prolonged catheterization, the frequent use of antibiotics, treatment with corticosteroids, comorbidities such as diabetes mellitus, fungal infections and especially candiduria are a possibility to take into account, not only as colonizing agent (asymptomatic candiduria) of any segment of the urinary tract, but can be the cause of abscesses, infection of the lithiasis and can become a symptomatic and invasive pathogen, (23-24) which was evaluated and ruled out in 10 patients of this report, by mycological cultures of the urine [25].

The presence of immunosuppression documented with studies of cellular and humoral immunity, due to the use of steroids and immunosuppressants for a long time, was present in $7.5 \%$ of the episodes, in a patient with demyelinating disease, as well as in two patients with SCI associated with alterations of the nutritional status due to co-morbidities such as pressure ulcer (present in 18\% of the episodes), the latter affecting the emotional state with chronic depression, both situations favor the immune alterations of the host and constitute risk factors added to the VN, that compromise the host's defenses against infection [26].

Isolated enterobacteria have a sensitivity of $83-100 \%$ for cefepime, amikacin and meropenem, constituting an excellent therapeutic resource when decision-making is necessary for patients 
with severe obstructive forms of pyelonephritis, as well as a sensitivity of $90-100 \%$ for nitrofurantoin; resistance to nalidixic acid, ciprofloxacin, sulfaprim, penicillins and cephalosporins between 60 - 80\%; behavior according to the institutional microbial map and according to a study carried out previously of the different resistance patterns of $E$. coli from urine cultures in hospital isolates, where there is a growing increase in resistance that is expressed from one to seven combinations of antimicrobials $[27,28]$.

The resistance mechanisms of the most frequent Enterobacteriaceae are related to resistance genes against antibiotics used in the urinary tract; plasmid-encoded or chromosomally encoded beta-lactamases, with broad activity against penicillins and cephalosporins $[29,30]$ and function by fractionation of the $\beta$-lactam ring, thus inactivating antibiotics, these plasmids carry other resistance genes that provide activity against other families of antimicrobials such as aminoglycosides, sulfonamides and quinolones, by transferring resistance to other antibiotics, which could be the mechanism of multi-resistance in these pathogens $[31,32]$.

\section{Conclusion}

Recurrent symptomatic bacteriuria and acute pyelonephritis are the most frequent clinical forms of cUTI in patients with neurogenic bladder, with E. coli being the most common germ, with an increase in the proportion of isolates of other enterobacteria. Associated risk factors are related to the use of intermittent or permanent catheterizations. Isolated Enterobacteriaceae are 80 - 100\% sensitive to amikacin, meropenem, cefepime, and nitrofurantoin, and $60-80 \%$ resistant to various families of commonly used antimicrobials: nalidixic acid, ciprofloxacin, sulfaprim, penicillins and cephalosporins.

The clinical evaluation and antimicrobial treatment for NV UTIC should be based on therapeutic protocols reasoned according to the form of presentation, microbial circulation and behavior of the sensitivity/resistance pattern, avoiding prophylactic use in asymptomatic forms and thus promoting optimization of antibiotics, essential tools of the program to reduce resistance in urinary infections at the hospital and global level.

\section{Interest Policy}

There are no conflicts of interest between the authors of the work.

\section{Ethical Conflicts}

All patients included in this series have in their medical history the informed consent document, for their incorporation into the neurological restoration program, which is signed by the patient and the family member.

\section{Bibliography}

1. Anthony J., et al. "Infections of the Urinary Tract". In: Wein A, Kavoussi L, Partin A, Peters C. Campbell-Walsh Urology. $11^{\text {th }}$ Edition. Amsterdam: Elsevier (2015): 237-303.

2. Hernández E., et al. "Características epidemiológicas, clínicas y microbiológicas de las infecciones nosocomiales urinarias en las lesiones medulares espinales". Actas Urológicas Españolas 31.7 (2007): 764-770.

3. Foxman B. "The epidemiology of urinary tract infection. Vigil HR and Hickling DR. Urinary tract infection in the neurogenic bladder". Nature Reviews Urology 7.12 (2010): 653-660.

4. Vigil HR and Hickling DR. "Urinary tract infection in the neurogenic bladder". Translational Andrology and Urology 5.1 (2016): 72-87.

5. Flores-Mireles AL., et al. "Urinary tract infections: epidemiology, mechanisms of infection and treatment options". Nature Reviews Microbiology (2015).

6. Pascuali P., et al. "Diagnóstico de infección urinaria en pacientes con vejiga neurogénica que practican cateterismo intermitente limpio". RevHosp Niños BAires. 54.246 (2012): 122-129.

7. Barber AE., et al. "Urinary Tract Infections: Current and Emerging Management Strategies". Clinical Infectious Diseases 57.5 (2013): 719-724.

8. Robino L., et al. "Intracellular Bacteria in the Pathogenesis of Escherichia coli Urinary Tract Infection in Children". Clinical Infectious Diseases 59.11 (2014): 58-64.

9. Madersbacher H. "The various types of neurogenic bladder dysfunction: an update of current therapeutic concepts". Paraplegia 28.4 (1990): 217-229.

10. Asociación Europea de Urología. Disfunción neurógena del tractus urinario inferior.

11. Toro I., et al. "Diagnóstico microbiológico de las infecciones urinarias". Enfermedades Infecciosas y Microbiología Clínica 33 (2015): 34-39.

12. Contreras OR., et al. "WO/1998/047999: Equipment, kit and method for microbiological diagnosis (1998).

13. Hooton TM., et al. "Diagnosis, Prevention and treatment of catheter-associated Urinary Tract Infection in Adults: 2009 International Clinical Practice Guidelines from the Infectious Diseases Society of America". Clinical Infectious Diseases 5 (2010): 625-663. 
14. Foxman B. "Urinary tract infection syndromes: occurrence, recurrence, bacteriology, risk factors, and disease burden". Infectious Disease Clinics of North America 28 (2014): 1-13.

15. Gould C. "Catheter-Associated Urinary Tract Infection (CAUTI) Toolkit. [Internet] Center for Diseases Control and Prevention (2017).

16. Vasudeva P and Madersbacher H. "Multifactorial causes of UTI in NGB. Factors implicated in pathogenesis of urinary tract infections in neurogenic bladders: Some revered, few forgotten, others ignored". Neurourology and Urodynamics 33.1 (2014): 95-100.

17. Nielubowicz G and Mobley H. "Host-pathogen interactions in urinary tract infection". Nature Reviews Urology 7 (2010): 430441.

18. Hannan TJ., et al. "Host-pathogen checkpoints and population bottlenecks in persistent and intracellular uropathogenic Escherichia coli bladder infection". FEMS Microbiology Reviews 36.3 (2012): 616-648.

19. Andersen TE., et al. "Escherichia coli uropathogenesis in vitro: invasion, cellular escape, and secondary infection analyzed in a human bladder cell infection model". Infection and Immunity 80.5 (2012): 1858-1867.

20. Grabe M., et al. "Guía clínica sobre las infecciones urológicas". European Association of Urology (2010).

21. Nicole LE., et al. "IDSA. Clinical Practice Guideline for the Management of Asymptomatic Bacteriuria". Clinical Infectious Diseases 68.10 (2019): e83-e75.

22. Ronald A. "The etiology of urinary tract infection: traditional and emerging pathogens". The American Journal of Medicine 113.1A (2002): 14S-19S.

23. Fisher JF., et al. "Candida urinary tract infection: pathogenesis". Clinical Infectious Diseases 52.6 (2011): S437-S451.

24. Thomas L and Tracy Chad. "Treatment of Fungal tractus urinary infección”. Urologic Clinics of North America 42 (2015): 473-483.

25. Kari JA., et al. "Reflujo vesicoureteral en niños". Anales de Urología 5.4 (2013): 232.
26. Zamora F., et al. "Influencia de la rehabilitación neuromuscular en el estado nutricional del paciente con trauma raquimedulardorsolumbar". Revista Cubana de Alimentación y Nutrición 21.1 (2011): 14-34.

27. Romero-Cullerés G. "Infección urinaria en pacientes con vejiga neurógena: patrones de resistencias de los uropatógenos más frecuentes”. Actas Urológicas Españolas 36.8 (2012): 482-310.

28. Martínez Arroyo M., et al. "Antimicrobial resistance patterns in uropathogens of hospitalized patients" (2010).

29. Cheng MF., et al. "Emergence of Extended Spectrum- $\beta$ Lactamase-Producing Escherichia coli 025b-ST131A Major Community-Acquired Uropathogen in Infants". The Pediatric Infectious Disease Journal 34.5 (2015): 469-475.

30. García Castellanos T., et al. "Mechanisms of resistance to betalactams in Gram-negative bacteria". Revista Cubana de Salud Pública 1 (2014): 40.

31. Argüez AR., et al. "Klebsiella pneumoniae y Escherichia coli productoras de betalactamasas en pacientes con infección del tracto urinario". Revista Cubana de Medicina Intensiva y Emergencia 14 (2015): 4.

32. Navarro F., et al. "Detection of resistance phenotypes in gramnegative bacteria”. Enfermedades Infecciosas y Microbiología Clínica Review 29.7 (2011): 524-534.

\section{Assets from publication with us}

- Prompt Acknowledgement after receiving the article

- Thorough Double blinded peer review

- Rapid Publication

- Issue of Publication Certificate

- High visibility of your Published work

Website: www.actascientific.com/

Submit Article: www.actascientific.com/submission.php Email us: editor@actascientific.com

Contact us: +919182824667 